\title{
РОЗРОБКА ПРОГРАМИ, ЯКА ГЕНЕРУЄ ЕМС ЗА ЗАДАНОЮ КОРИСТУВАЧЕМ ФОРМОЮ, 3 МОЖЛИВІСТЮ ДОДАТИ ПЕРЕШКОДИ
}

\author{
Ізюмкін П.І., студ. \\ petro.i.izyumkin@gmail.com \\ Кафедра біомедичної інженерії \\ Національний технічний університет України \\ Київський політехнічний інститут імені Ігоря Сікорського» \\ м. Київ, Україна
}

\begin{abstract}
Анотація. Була розроблена програма для синтезу ЕМС по заданій користувачем формі. Проаналізовано модель генерації сигналів по структурі близьких до реального ЕМС. На цій основі створено програму генеруюча ЕМС з можливістю змінювати форму сигналу, частоту, а також додавати різні шуми і перешкоди.
\end{abstract}

Ключові слова - Генератор сигналу, електроміографія, електроміосигнал, довільна форма, LabView.

\section{І. ВСТУП}

Електрофізіологічні

(ЕФ) сигнали використовується вже довгій час, та досі $є$ i навіть набуває все більшій актуальності. Електроміосигнал це один з ЕФ сигналів, якій використовується в діагностиці нервовом'язових та м'язових захворювань, протезуванні i реабілітації та при дослідженнях роботи опорно-рухового апарату людини.

При застосуванні електроміографії використовують спеціальні вимірювальні пристрої, електроміографи, які мають відповідати певним вимогам по точності, завадостійкості та шумозаглушення зазначеним у міжнародних та державних стандартах. Тому, при розробці даних пристроїв, необхідно проводити перевірку вимірювальних характеристик. Для цього використовують реальні або синтезовані сигнали ЕМГ. Також, при аналізу сигналів використовують програмне забезпечення, яке має визначати частотні та морфологічні особливості сигналу. Для перевірки достовірності цього аналізу також застосовують сигналі ЕМГ.

Тому на етапу моделювання роботи вимірювального пристрою чи при розробці ПЗ необхідно використовувати цифрові сигнали, і крім того необхідні сигнали різної форми, різного співвідношення сигнал/шум і безлічі інших варіацій. Використання реального сигналу обмежено об'ємом бази даних, а запис сигналів по кожній 3 цих варіацій буде недоцільним. Тому буде корисним використовувати синтезований сигнал 3 більш широкими можливостями варіації.

Для цих цілей необхідно мати генератор EMC 3 можливостями змінення форми сигналу, наявності шумів та частоти слідування імпульсів.

Тому маємо актуальну задачу розробки програми, яка здібна генерувати сигнал 3 частотними та морфологічними характеристиками відповідними реальним сигналам ЕМГ, додавати шуми різного роду та співвідношення а також зберігати сигнал в зручній для використання формі..

\section{II. МЕТА ДОСЛІДЖЕННЯ}

Метою роботи є розробка програмного забезпечення для синтезу ЕМС по заданій користувачем формі з можливістю додавання шумів i перешкод. А також, перевірка синтезованого сигналу на відповідність реальному сигналу ЕМГ. 


\section{III. МАТЕМАТИЧНА МОДЕЛЬ}

Поверхневий ЕМС являє собою інтерферіційну суму сигналів всіх рухових одиниць (РО) поряд з реєструючим пристроєм.

В роботі [1] представлена модель поверхневого сигналу ЕМС в якості суми послідовності моноімпульсів декількох РО, яка може бути виражена у формулі:

$$
U=\sum_{k=1}^{K} \sum_{n=1}^{N} f\left(t-\tau_{n}-\Delta t\right),
$$

де $\mathrm{t}$ - час; $\tau_{n}$ - інтервал між моноімпульсами; $\Delta t$ - випадкова зміна інтервалу; $f(t)$ - функція ПДЕ у вигляді моноімпульсу Гауса; $\mathrm{n}=1,2 \ldots$ $\mathrm{N}$ - кількість імпульсів однієї $\mathrm{PO} ; \mathrm{k}=1,2 \ldots \mathrm{K}$ - кількість РО.

Моноімпульс, чи моноцикл, Гаусу являє собою першу похідну від функції розподілу Гауса. Він розраховується по формулі:

$$
f(t)=A \sqrt{2 \pi e} \frac{t}{\Delta t} \exp \left(-\frac{t^{2}}{\Delta t^{2}}\right)
$$

де $\mathrm{t}$ - час, $\Delta t$ - тривалість імпульсу, А амплітуда.

Для синтезу ЕМС довільної форми необхідно кожен раз задавати частоту імпульсів та кількість РО.

Однак для генерації сигналу заданої форми необхідно мати лише один параметр. Тому будемо задавати умовне зусилля м'язу, а частота та кількість РО будуть пропорційні цьому значенню.

Таким чином алгоритм генерації ЕМС має вигляд:

- Задається послідовність частот слідування та загальна тривалість сигналу;

- розрахунок параметрів генерування моноімпульсу для однієї частоти, а саме: центральна частота імпульсу, частота слідування імпульсів, випадкова зміна інтервалу між імпульсами, амплітуда;

- генерування одного імпульсу по заданим параметрам по моноімпульсу гауса;

- послідовне складання імпульсів, що являє собою сигнал однієї РО;
- сумування послідовностей імпульсів в один сигнал, якій являє собою інтерферіційну суму сигналів декількох РО;

- послідовне складання сигналів для різних частот слідування;

- додавання шумів.

\section{POЗРОБКА}

Програма повинна забезпечувати можливість виконання перерахованих нижче функцій:

Генерація ЕMC за заданою користувачем формою;

b) Додавання різних шумів та перешкод в сигнал;

c) Візуалізація синтезованого сигналу;

d) Збереження отриманого сигналу для подальшого його використання.

Також для зручності було вирішено додати можливість генерації сигналу 3 постійною частотою та додати шаблонні форми, які б можливо було встановити та змінювати.

Ієрархічна структура представлена на рисунку 1.

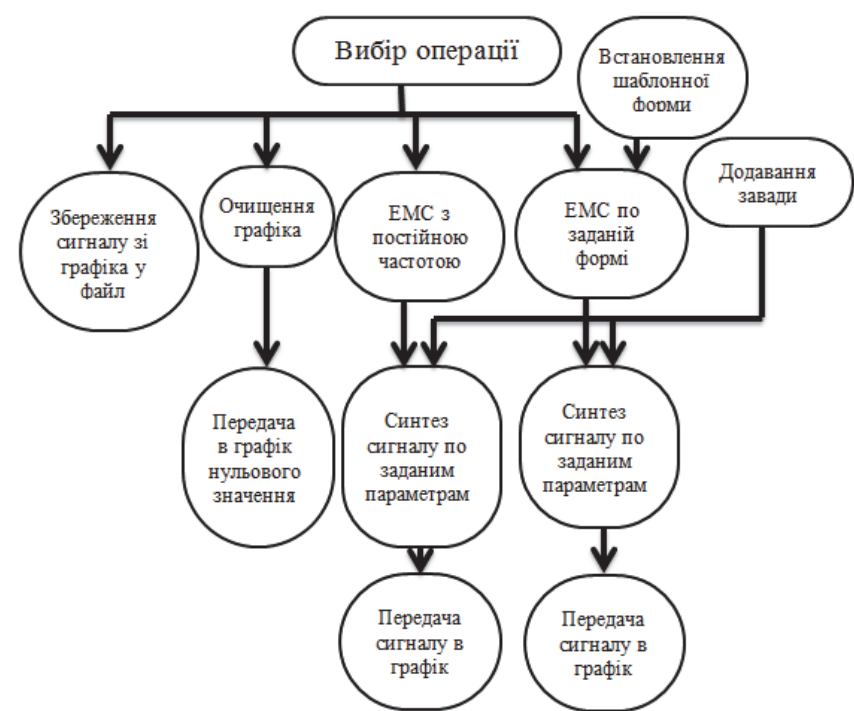

Рисунок 1. Іерархічна структура програми.

Таким чином, маємо чотири функціональні опції, які виконують певні дії (збереження сигналу у файл, очищення графіку, генерування сигналу за формою, генерування однакової частоти), додаткову 
опцію встановлення шаблонної форми та вибіркову опцію додавання шумів.

\section{V. ПРОГРАМУВАННЯ}

Код програми був виконаний середовищі NI LabVIEW 2010. Інтерфейс користувача та код програми представлені на рисунках 2 і 4.

Головною функціональною частиною коду $є$ блок синтезу послідовності моноімпульсів однієї рухової одиниці. Цей сегмент коду базується на математичній моделі iз джерела [1]. Цей код зображений на рисунку 4, внутрішній цикл. Основою генератора є функція Gaussian Monopulse.vi, яка генерує одиночні імпульси. Для цієї функції задаються п'ять параметрів: частота моноімпульсу, кількість відліків, амплітуда, затримка (у відліках) та дельта, яка змінює ширину імпульсу. Частота моноімпульсу була використана 100 Гц, що відповідає тривалості 10 мс. Це значення може бути різним для різних м'язів, однак підходить для початкового налагодження програми. Кількість відліків розраховується шляхом ділення частоти дискретизації на частоту. Амплітуда взята 1 мB, що відповідає реєструємої амплітуді однієї РО[3]. Затримка задається в половіну кількісті відліків з гауссовим розбігом від $-80 \%$ до $+80 \%$. Дельта задається рівної 1 .

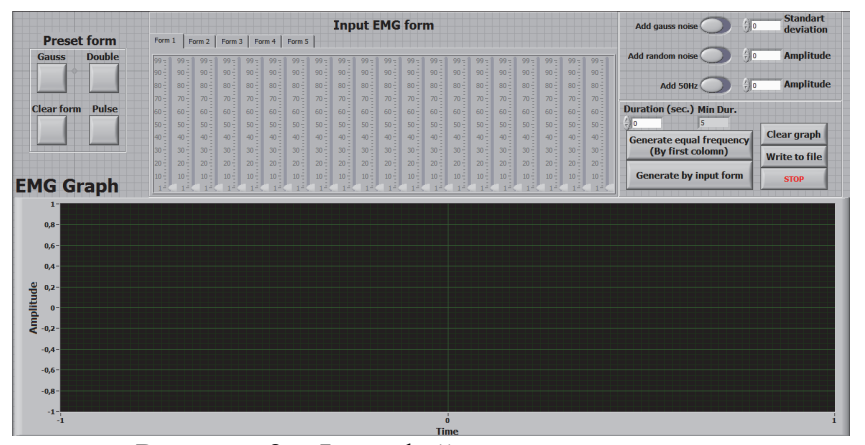

Рисунок 2 - Інтерфейс користувача.

Зовнішній цикл на рисунку 4 робить двомірний масив, який являє собою сукупність послідовностей моноімпульсів декількох рухових одиниць. Кількість рухових одиниць тут розраховується як половина частоти імпульсів. Не вдалося знайти точної залежності кількості РО від частоти, тому було використано це значення. Максимальна число рухових одиниць - 40, мінімальне - 5. Ці значення використанні для початкового налагодження програми. Вони відрізняються для кожного м'яза, тому необхідно їх задавати для модуляції конкретного м'яза. Побудовані двомірні масиви підсумовуються та складаються в одномірний масив за допомогою функцій Insert Array (рисунок 5). 3 початку підсумовування у циклі, потім складання в одномірний масив за допомогою вузлу

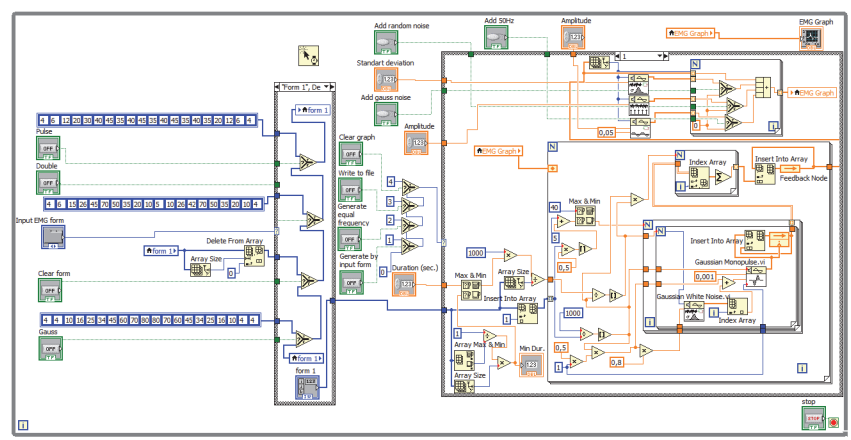

Рисунок 3 - Код програми в LabVIEW, загальний вигляд.

Для функціï "Generate by input form" тривалість розраховується як найбільше значення між введеною користувачем тривалістю та мінімальною тривалістю. Мінімальна тривалість розраховується як множення оберненого значення мінімальної частоти на кількість частот у вхідному масиві. Вхідний масив частот саме і ініціює цикл, в якому генеруються масиві сигналу для кожної частоти.

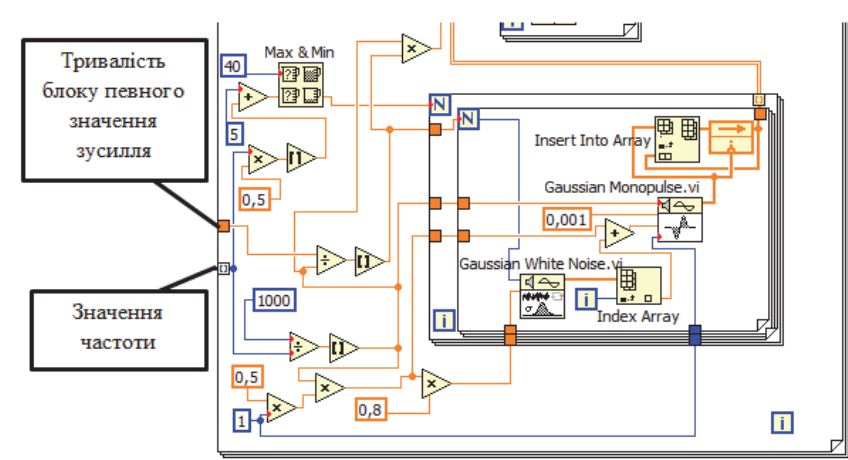

Рисунок 4 - Код програми в LabVIEW, генерування послідовності імпульсів однієї частоти.

Для функції "Generate equal frequency нема $\epsilon$ циклу генерації так як всього одна частота. Тому в даному випадку генерується двомірний масив, якій потім підсумовується у одномірний. Задається лише одна частота та тривалість, яка також порівнюється 3 мінімальною тривалістю. 


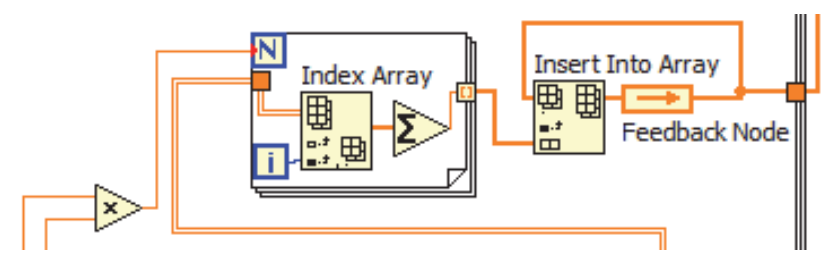

Рисунок 5 - Код програми в LabVIEW, підсумовування та складання послідовностей.

Надалі до синтезованого сигналу додаються завади та перешкоди, за потреби користувача (рисунок 6). Для шумів задаються параметри. Для перешкоди 50 Гц та випадкового шуму задається амплітуда, для гаусового шуму задається стандартне відхилення значення. Після цього сигнал виводиться на графік.

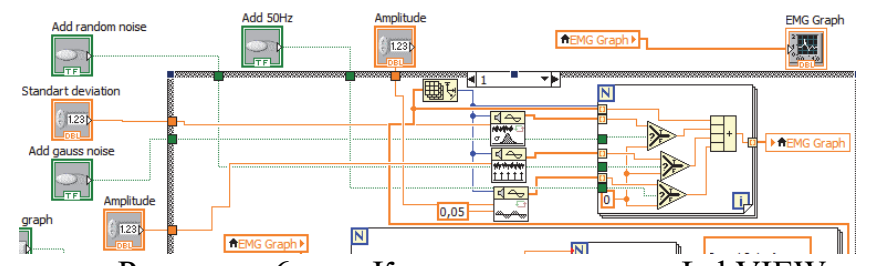

Рисунок 6 - Код програми в LabVIEW, додавання перешкод.

\section{. КОРИСТУВАЛЬНИЦЬКИЙ ІНТЕРФЕЙС}

Управління програмою відбувається через GUI-інтерфейс (рисунок 2). Для виконання тієї чи іншої функції необхідно нажаті відповідну кнопку (Рисунок 7, нижня частина). Функція "Clear graph" - очищає графік від виведених до цього сигналів. Функція "Write to file" - записує сигнал 3 графіка в обраний користувачем файл. Функція "Generate equal frequency (by first column)" генерує ЕМС по заданій користувачем частоті, за допомогою першого стовпа регулятора форми. Функція "Generate by input form" генерує ЕМС по заданій користувачем формі, за допомогою регулятора форми.

За допомогою блоку додавання шумів $\mathrm{i}$ перешкод можна додати гаусів шум, випадковий шум і перешкоду в 50 Гц (Рисунок 7 , верхня частина).

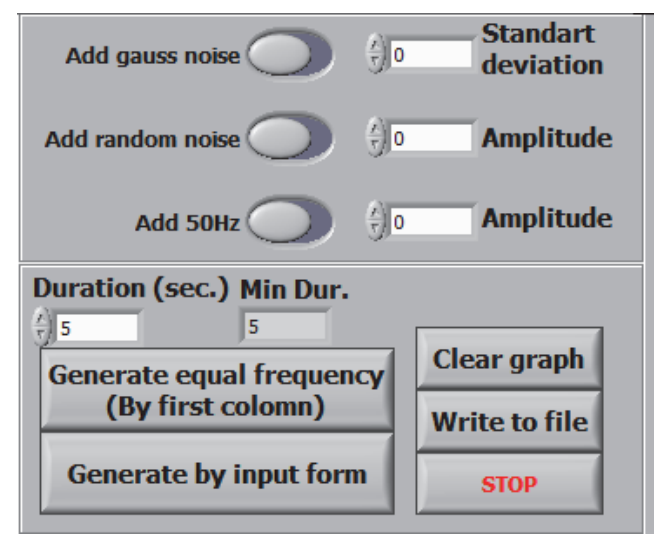

Рис. 7 - Головні елементи керування та блок додавання перешкод.

Регулятор форми "Input EMG from", зображений на рисунку 8 , має п'ять вкладок, які зберігають в пам'яті виставлену форму, що дозволяє синтезувати більш складні сигнали, по черзі перемикаючи форми, i додаючи їх в графік. Попередньо встановити форму сигналу на регулятор форми можна за допомогою блоку "Preset form". Даний блок встановлює регулятор форми в позиції: "Gauss", "Double”, "Clear form” (повністю очищає форму на цій вкладці), "Pulse”.

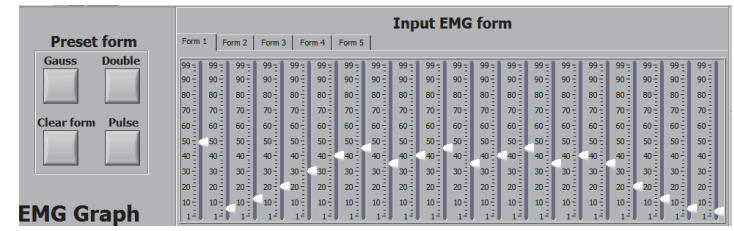

Рис. 8 - Регулятор форми та блок попереднього встановлення форми.

Всі отримані сигнали виводяться в порядку синтезу на графік "EMG graph" i залишаються на ньому до очищення графіка за допомогою функції “Clear graph”.

\section{VII. ЗАСТОСУВАННЯ}

Програма призначена для генерації EMC по заданих параметрам користувача: форма, тривалість, частота, співвідношення сигнал/шум. Має власний GUI-інтерфейс і може використовуватись при розробці електроміографа для тестування апарату на етапі моделювання, або для тестування роботи програм для аналізу електроміосигналів.

Регулятор форми дозволяє генерувати сигнал будь-якого виду. Для зміни інтенсивності сигналу в ділянці необхідно рухати білий трикутник. 


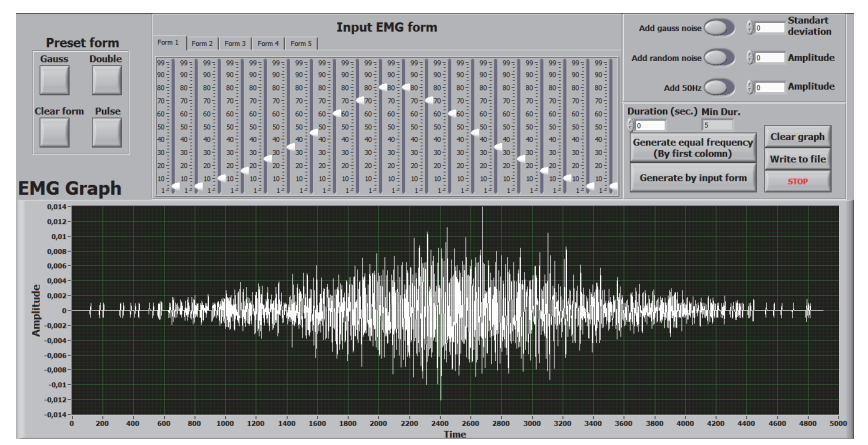
Gauss form".

Рис. 9 - Приклад синтезованого сигналу. "Preset

Додавання шуму різного роду дозволяє змоделювати сигнал наближений до реального при різноманітних умовах.

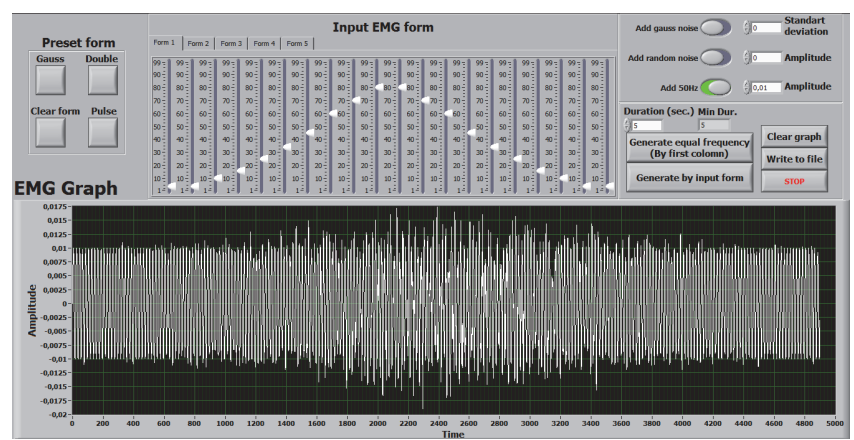

Рис. 10 - Приклад синтезованого сигналу 3 додаванням перешкоди 50 Гц.

Для подальшого використання сигнал зберігається у файл без формату у вигляді послідовності числових значень. Такій файл може використовувати будь-яка програма, яка здібна зчитувати файли не спеціального формату.

\section{VIII. ПОРІВНЯННЯ}

Подальше для перевірки відповідності генеруємого сигналу реальному сигналу ЕМГ проведемо порівняння п'яти згенерованих сигналів і п'яти реальних сигналів та їх спектрів. 3 джерела [7] були взяти записані сигнали ЕМГ, які були представлені Університетом Патр, Греція, м. Патр. Сигнали були зняті $з$ передпліччя під час утримання вантажу рукою в положенні зображеному на рисунку 11. В базі даних були представлені два канали i для кожного 3 них було по 30 записаних сигналів. Випадковим образом зі всіх цих сигналів булі обрані п'ять.

Графікі сигналів та їх спектрів були построєні у середовищі GNU Octave, яка являє собою безплатний аналог Matlab.
Спектри сигналів були построєні за допомогою функції fft при використанні вікну Бартлетта.

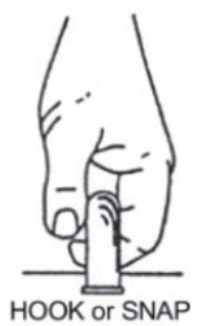

Рис. 11 - Положення руки при запису сигналів ЕМГ.

Також зі спектрів записаних сигналів були видалені постійні складові, які спотворювали спектр.

Для порівняння були згенеровані сигнали п'яти значно різної форми. Були згенеровані сигнали: 1,2,3 - пульсуючі сигнали низької, середньої та максимальної частоти, 4 два великих імпульси та 5 - один імпульс максимальної дозволенної частоти (рисунок

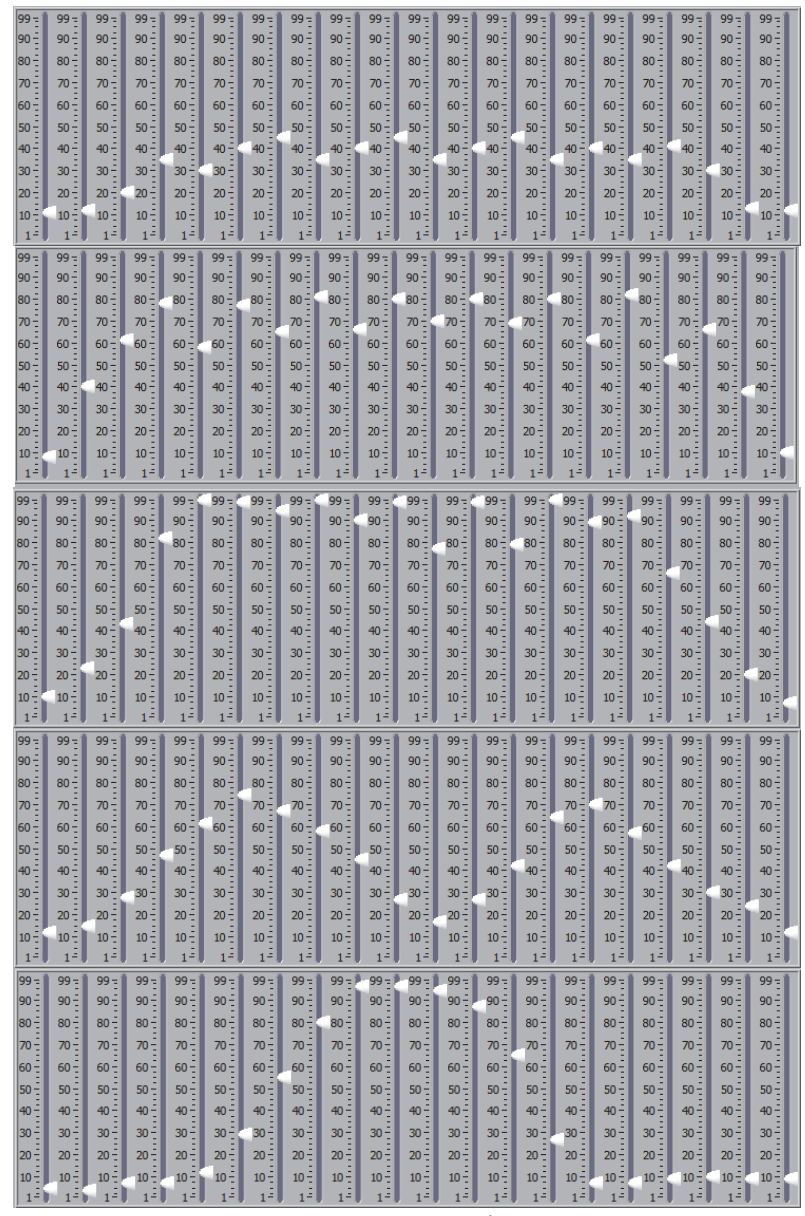

Рисунок 12 - Синтезовані сигнали

Сигнали та їх спектри записаних 
сигналів зображені на рисунку 13. ліворуч сигнали, праворуч їх спектри. Представлені сигнали: 1 - 22 запис першого каналу, 2 - 21 запис першого каналу, 3 - 11 запис другого каналу, 4 - 4 запис другого каналу, 5 - 20 запис першого каналу.
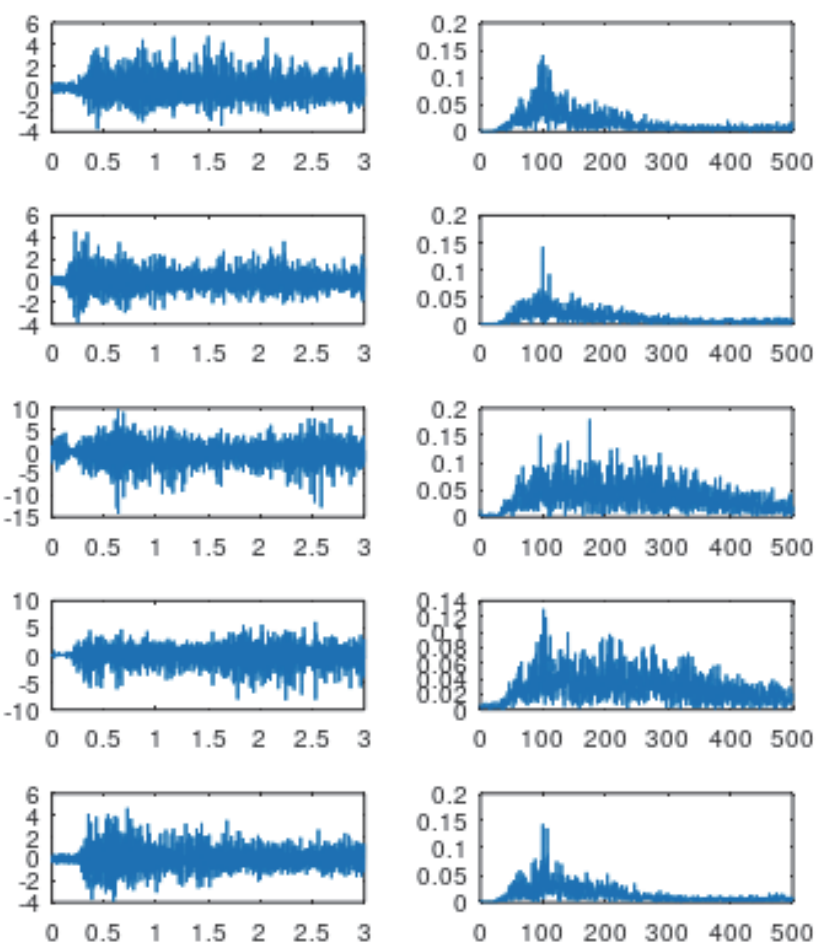

Рис 13. - Записані сигнали (ліворуч) та їх спектри (праворуч). На графіках ліворуч: по осі абсцис час, с. по осі ординат - напруга, мВ. Праворуч: по осі абсцис - частота, Гц. По осі ординат - вклад частот у сигнал.

Графіки синтезованих сигналів та їх спектри зображені на рисунку 14. Ліворуч сигнали, Праворуч їх спектри.
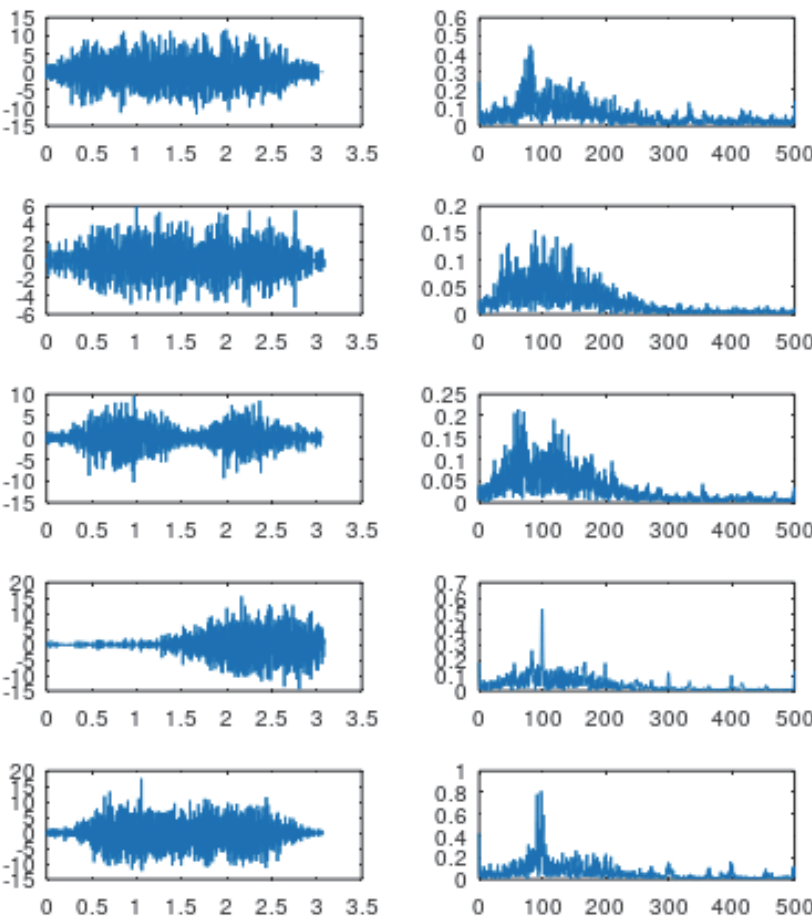

Рис 14. - Синтезовані сигнали (ліворуч) та їх спектри (праворуч). На графіках ліворуч: по осі абсцис час, с. по осі ординат - напруга, мВ. Праворуч: по осі абсцис - частота, Гц. По осі ординат - вклад частот у сигнал.

Порівнюючи спектри сигналів можна бачити, що структура спектрів синтезованих сигналів схожа на структуру записаних сигналів. Однак спектри сигналів 3 другого каналу відрізняються шириною значимих частот. Це вірогідно визвано тім, що другій канал можливо знімається в іншому місці та охвачує більшу кількість м'язів і цим самим більшу кількість РО. Однак не відомо де знімаються сигнали та структура самих сигналів, тому не можливо робити висновки про чинники різниці у спектрах.

Проте спектри сигналів першого каналу та спектри синтезованих сигналів мають схожу структуру, що свідчить про відповідність синтезованих сигналів реальним. Але, враховуючи різницю зі сигналами другого каналу, слід вдосконалити програму для того що б було можливо генерувати сигнали різного складу.

\section{ІХ. ВИСНОВОК}

Результатом роботи $є$ розроблена програма для генерації сигналу ЕМГ. Програма виконує всі заложенні функції. Вона дає можливість синтезувати ЕМС по довільній формі, додати до сигналу перешкоди та 
зберегти сигнал у файл для подальшого використання.

Було проведено порівняння синтезованого сигналу 3 реальним. В ході порівняння було виявлено, що сигнали, які генеруються, відповідають реальним сигналам по частотному спектру. Приклади реальних сигналів знімались 3 двох різних каналів. При чому синтезовані сигналі відповідають реальним сигналам с першого каналу, та відрізняються від сигналів другого каналу шириною спектра.

Оскільки в джерелі [7] не зазначено чим відрізняються канали, тому неможна зробити висновок, в чим зумовлена різниця сигналів. Проте, оскільки синтезовані сигнали відповідають половині 3 представлених сигналів, можна вважати, що програма вірно побудована та може синтезувати відповідні сигнали ЕМГ. Але вона потребує вдосконалення, щоб мати можливість синтезувати сигнали будь-якої ділянці тіла. Це потребує як подальшого програмування, так i більш глибоко дослідження структури ЕМГ сигналів.

Також пропонується розширити функціонал програми для збільшення іiі можливостей.

Можливі вдосконалення:

- Зробити регульовану залежність кількісті рухових одиниць від частоти імпульсів, та максимальну і мінімальну кількість.

- Зробити вибір ділянці тіла з відповідною зміною всіх необхідних параметрів, що дозволить генерувати будь-які ЕМГ сигнали.
- Розширити набір перешкод які додаються, оскілки у реальному сигналі перешкод може бути набагато більше.

- Розширити набір шаблонів форм, які б відповідали поширеним формам ЕМС.

- Додати можливість синтезувати ЕМС при патологіях, оскільки електроміограф використовується для діагностики патологій.

- Додати можливість синтезувати ЕКГ сигнал, оскільки для розробки електрокардіографів теж буде вигідно використовувати синтезований сигнал.

\section{ПЕРЕЛІК ПОСИЛАНЬ}

[1] Шайдук А. М., Останин С. А. Моделирование электромиографического сигнала средствами LabVIEW / Известия Алтайского государственного университета. Барнаул: Изд.-во Алт. гос. ун.-та. - Ч.1(65), 2010. - С. 196-201. [2] R. Bitter, T. Mohiuddin, M. Nawrocki. LabView: Advanced Programming Techniques, Second Edition. CRC Press, 2017 г. $520 \mathrm{c}$.

[3] Николаев С.Г. Практикум по клинической электромиографии. Издание второе, переработанное и дополненное. Иваново 2003. 264 с.

[4] Медицинская физиология по Гайтону и Холлу / Дж.Э. Холл / Пер. с англ.; Под ред. В.И. Кобрина, М.М. Галагудзы, А.Е. Умрюхина. 2-е изд., испр. и доп. - М.: Логосфера, 2018. $1328 \mathrm{c}$.

[5] Исмайылова Камала Ширин. "Факторы, влияющие на искажение измерительной информации в электромиографии" Наука, техника и образование, no. 10 (40), 2017, pp. 21-23.

[6] Селиванова К Г., Аврунин О. Г., Галетка А. А. Математическое моделирование электромиографического сигнала. Вісник НТУ “ХПІ», No36(1079), 2014.С. 31-39.

[7] https://archive.ics.uci.edu/ml/machine-learning-databases/00313/ 


\title{
РАЗРАБОТКА ПРОГРАММЫ, ГЕНЕРИРУЮЩЕЙ ЭМС ПО ФОРМЕ, ЗАДАННОЙ ПОЛЬЗОВАТЕЛЕМ, С ВОЗМОЖНОСТЬЮ ДОБАВЛЕНИЯ ШУМОВ
}

\author{
Изюмкин П.И., студент \\ petro.i.izyumkin@gmail.com \\ Кафедра биомедицинской инженерии \\ Национальный технический университет Украины \\ «КПИ им. Игоря Сикорского», \\ Киев, Украина
}

\begin{abstract}
Аннотация. Разработана программа синтеза ЭМС по пользовательской форме. Проанализирована модель генерации сигналов по структуре, близкой к реальной ЭМС. На этой основе была создана программа генерации ЭМС с возможностью изменения формы сигнала, частоты и добавления различных шумов и помех.
\end{abstract}

Ключевые слова - генератор сигналов, электромиография, электромиосигнал, произвольная форма, LabView..

UDC 612.741.1

\section{DEVELOPMENT OF A PROGRAM THAT GENERATES EMC IN A USER-DEFINED FORM, WITH THE ABILITY TO ADD NOISES}

Izyumkin P.I., student petro.i.izyumkin@gmail.com Department of Biomedical Engineering National Technical University of Ukraine «Igor Sikorsky Kyiv Polytechnic Institute», Kyiv, Ukraine

Abstract. A program for the synthesis of EMSs according to a user-defined form was developed. The model of signal generation on structure close to real EMS is analyzed. On this basis, an EMS generating program was created with the ability to change the signal shape, frequency, and add different noise and interference.

Key words - Signal generator, electromyography, electromyosignal, arbitrary form, LabView. 